\title{
Optimization Method of Technical Solutions in Premium Power Park Considering Customers' Power Quality Demand
}

\author{
Xuna. Liu' ${ }^{1, a}$, Da. Li ${ }^{1, b}$ and Dawei. Zhao ${ }^{1, c}$ \\ ${ }^{1}$ State Grid Sichuan Economic Research Institute, Sichuan Province, China \\ aliuxuna86@126.com, ${ }^{b}$ 5670555@qq.com, ${ }^{c}$ 147654563@qq.com
}

\begin{abstract}
Keywords: Premium Power Park; customers' demand; process immunity time; power quality; optimization model
\end{abstract}

Abstract. Premium Power Park (PPP) is a technical solution to solve the regional high-quality power supply problems. The technical optimization method is the premise of planning and constructing. To meet various power demands of different customers, the concept of process immunity time is lead up in this paper. Considering the response characteristic of process to sag and the variation curve of physical parameters, the method of quantification for customers' power quality demands is proposed. On this basis, optimization model is established by constraints of customers' demands and taking the minimum cost as the objective. And its corresponding algorithm based on Tabu search method is researched. The proposed method is applied to a typical PPP and it is proved to be accurate and valid. The results show that this method can meet each customer's demand, meanwhile, ensure the minimum of total investment.

\section{Introduction}

With the extensive application of high-technology, the disturbance such as voltage sag has been became an urgent problem in modern power system. As an effective solution, Premium Power Park has been established in in Sendai, Delaware, etc [1]. A PPP can be defined as an electric consumption pattern for different power quality demands of customers, depending proper custom power devices [2]. Most of all, the optimization method of technical solutions in custom power is the key for the construction of PPP, which impacting on the investment directly. Therefore, this study has important theoretical and practical significance.

There are many different between PPP and traditional distribution network. The former focuses on the power supply mode and technical cost in from customers' side while the grid structure for the latter. Currently, there is less study on the quantitative method of customers' demand and the optimization model of custom power devices in PPP. In the existing PPPs, the optimal configuration method is always based on customers' power quality demand. The differentiation of custom devices has been used to meeting the classification of power demands. However, there is short of intensive study about the quantitative classification in existing research.

Based on the concept of Process Immunity Time (PIT) proposed by IEC C4.110 in 2010 [3], the response characteristic of industrial processes for voltage sag can be depicted by physical parameter curves of process. And customers' demands could be quantified through the mapping relationship from operating state of process to power quality. The optimization model of Premium Power Park is established which targets the minimum cost with Tabu search algorithm. The proposed method has been proved by a typical industrial Park based on MATLAB and PSCAD/ EMTDC simulation.

\section{Quantitative Method of Customers' Demand}

Process Immunity Time. The assessment of customers' demands for power quality is the basis of the technical solutions in the PPP which can provide multiple choices for power quality. The customers in PPP consists of various progresses, therefore, it is necessary to confirm the immunity of process for voltage sag which is the most serious power quality problems [4]. Process Immunity Time (PIT) is proposed by Working Group IEC C4.110 has been defined as the duration of the physical parameter 
from normal to critical value when process suffering voltages sag, which is shown in Fig. $1(a)$ [3]. Where $P_{\text {nom }}$ is the rated value of physical parameter, $P_{\text {limit }}$ is the acceptable critical value of physical parameter, $t_{1}$ is the initial time of sag, $\Delta t$ is latency time, $t_{2}$ is the switching time of parameter from normal to unacceptability. PIT is an important index to measure the immunity of progress suffering certain voltage sag. As shown in Fig. $1(b)$, with the decrease of magnitude of voltage sag (which means residual voltage in full), PIT becomes shorter gradually, and therefore, the PIT of a progress can be presented by a group of families of curves.

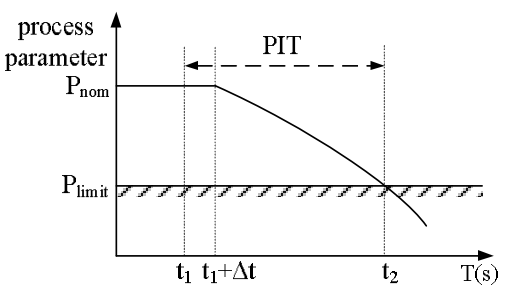

(a) PIT under a single magnitude of voltage sag

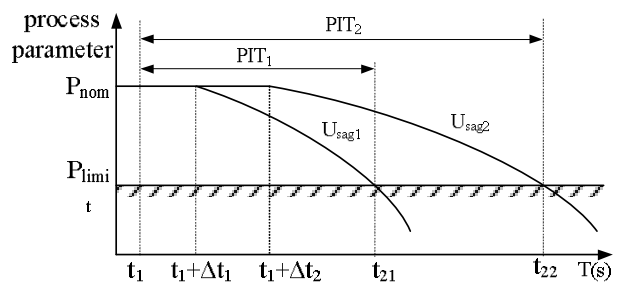

(b) PITs under diverse magnitudes of voltage sag

Fig. 1 Process immunity time (PIT)

Quantitative Demand of Customer. Operational status can be reflected by physical parameters; therefore, the changing curve of physical parameter can be used to depict the response characteristic of industrial process for voltage sag. Furthermore, customers' demands for power quality can also be determined according to the acceptable limits of physical parameters. According to the property that physical parameters curve is changing while suffering sag of different magnitude, PIT can be determined combined acceptable limits of physical parameters $\left(P_{\text {limit }}\right)$. So when the PIT is longer than duration, customers' demand can be satisfied. And in general, the duration of voltage sag has been determined by actuation time of relay protection. So the acceptability of customers for voltage quality could be predicated by comparing the PIT with duration.

Assuming a process encounter short disturbance $\left(U_{\text {sag }}\left(U_{\text {sag1 }}>U_{\text {sag2 }}>U_{\text {sag3 }}\right)\right.$ represents magnitude, $T_{\text {sag }}$ represents duration), the curve of physical parameter is shown in Fig. 2. With diminution of magnitude, the index of process immunity time presents the following characteristics: $P I T_{1}>P I T_{2}>P I T_{3}$ and $T_{\mathrm{sag}}=P I T_{2}$. As shown in Fig. 2, if the magnitude is lower than $U_{\mathrm{sag} 2}$, PIT will be less than $T_{\mathrm{sag}}$ and that will cause the physical parameters much lower than $P_{\text {limit }}$, which led to the short disturbance cannot meet the needs of the process. On the other hand, when the magnitude is higher than $U_{\text {sag2, }}$ PIT will be longer than $T_{\text {sag }}$ and cause the physical parameters much greater than $P_{\text {limit, }}$, which led to the short disturbance can meet the needs of the process. Therefore, for this progress, its acceptable critical

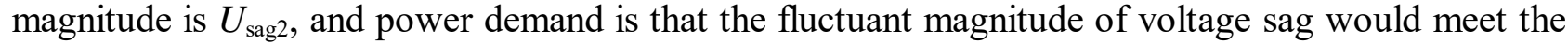
conditions that: $U_{\text {demand }} \geqslant U_{\text {sag2. }}$. Similarly, the quantitative demand of different progresses can be got in the same way, which is shown in Table 1.

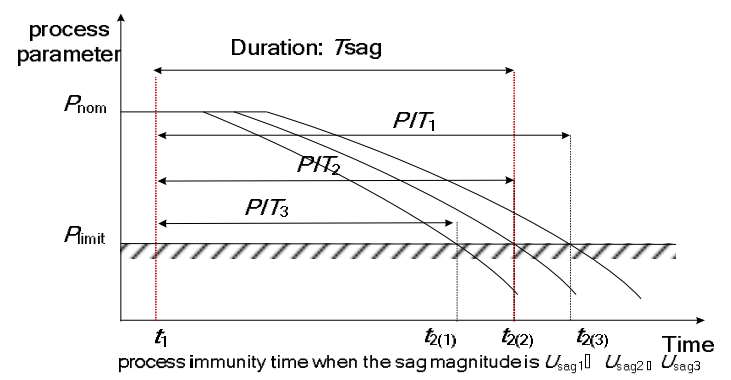

Fig. 2. Physical parameter variation under different short-duration voltage variations amplitude

Table 1. Short-duration voltage quality demand quantification of customers

\begin{tabular}{cc}
\hline Customer & Demand of power quality \\
\hline Process 1 & $U_{\text {demand(1) }} \geqslant U_{\text {sag(1) }}$ \\
Process 2 & $U_{\text {demand(2) }} \geqslant U_{\text {sag(2) }}$ \\
$\ldots$ & $\ldots$ \\
Process n & $U_{\text {demand(n) }} \geqslant U_{\text {sag(n) }}$ \\
\hline
\end{tabular}




\section{Optimal Model of Premium Power Park Configuration}

The Typical Structure of PPP. The typical power supply mode of PPP is to provide electric for different customers of various demands respectively with multiple feeders in one PCC bus by installing appropriate custom power devices. Therefore, the essential work of optimal configuration of PPP is the classifiable configuration of custom power devices according to customers' demands. Based on the existing demonstration projects and considered the quantitative requirement of different processes for power quality, the configuration structure of PPP which taking multiple DVRs to compensate customers' demands for voltage variation is proposed in this paper as shown in Fig.3.

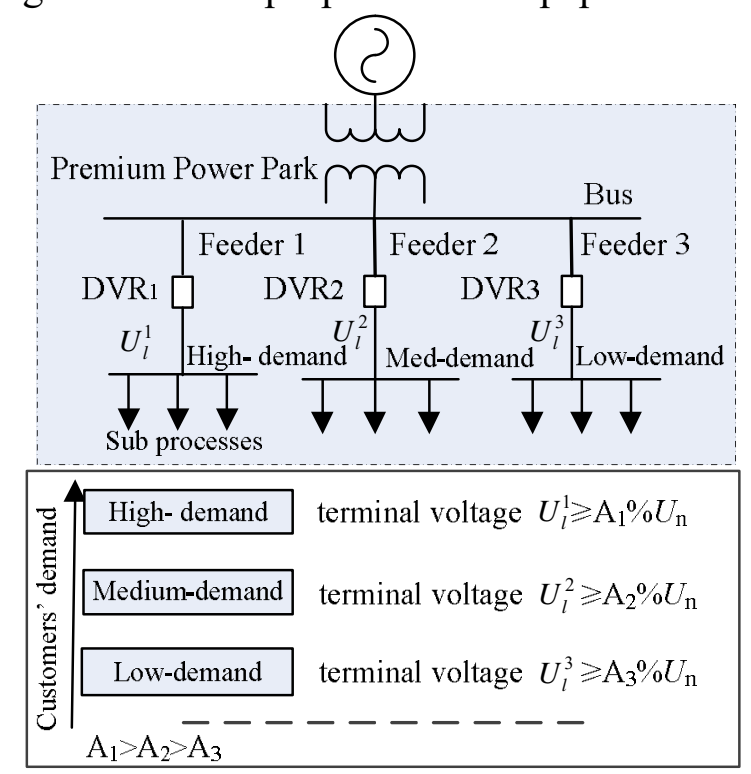

Fig. 3. The typical structure of premium power park

Optimal Model of PPP Configuration. Premium Power Park is a flexible, friendly and terminal grid. The key of Premium Power Park configuration is to minimize the total cost of custom power devices while ensuring different power requirements of customers. The number and capacity of DVR are primary problem, which can be gain on the basis of compensatory voltage magnitude. So the optimal configuration model has been established by the constraints of meeting customers' demand for terminal voltage of progress and the minimum cost is taken as the objective.

Premium Power Park is a flexible, friendly and terminal grid. The key of Premium Power Park configuration is to minimize the total cost of custom power devices while ensuring different power requirements of customers. The number and capacity of DVR are primary problem, which can be gain on the basis of compensatory voltage magnitude. So the optimal configuration model has been established by the constraints of meeting customers' demand for terminal voltage of progress and the minimum cost is taken as the objective. For the objective function:

$$
\min C o s t=\sum_{i=1}^{N D} D \cos t_{i}+\sum_{j=1}^{B R} L \cos t_{j}
$$

Where ND $=$ the number of compensatory devices; $\mathrm{BR}=$ the number of line; $\mathrm{D}_{\text {cost }}=$ the cost of compensatory devices $i$; $\mathrm{L}_{\text {cost } j}=$ the cost of line $j$.

Assuming the phase of output voltage of DVR around sag and the voltage in system remain the same, the constraint can be determined as:

$$
\begin{aligned}
& U_{s a g}^{t} \geq U_{\text {demand }}^{t} \\
& S_{D V R}=\sum_{t=1}^{T}\left(1-U_{\text {sag }}^{t}\right) S_{L}^{t} \\
& D \cos t_{i}=f\left(S_{D V R}^{i}\right)
\end{aligned}
$$


Where $U_{\text {sag }}^{t}=$ terminal voltage magnitude of feed connected with process $t ; U_{\text {demand }}^{t}=$ the voltage magnitude after compensatory by DVR; $\mathrm{S}_{\mathrm{DVR}}=$ the total; $S_{L}^{t}=$ the capacity of DVR connected to feeder $t ; f(x)$ represents the function of capacity - investment cost, which is shown in Fig.4 [5].

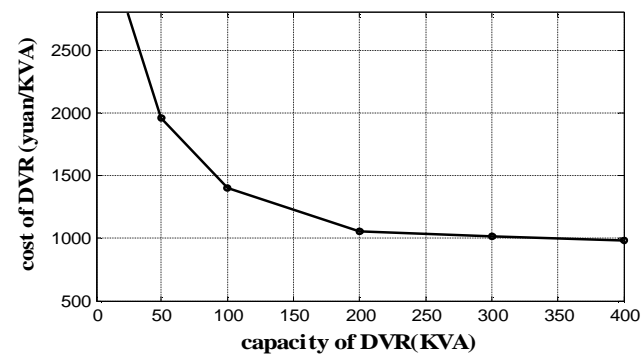

Fig. 4. DVR cost per kVA

Optimization procedure. The optimization procedure is summarized as follows:

Step I. Determine the physical parameters $\left(P_{\text {nom }}, P_{\text {limit }}\right)$ based on the structure, function and operation principle of each progress. And generate physical parameters curve and PIT value under different magnitude of sag using simulation of PSCAD/EMTDC.

Step II. According to the PIT values under different voltage magnitude and maximum duration of sag, determine the critical acceptable voltage magnitude of each progress, and generate voltage quality demand table in PPP.

Step III. Establish the PPP considering geographic location by the constraints of meeting customers' demand and the minimum cost as the objective.

\section{Optimization Algorithm}

The configuration optimization model expressed by the Eq. 1 to 4 is a combinatorial optimization problem. Tabu search algorithm is adopted in this paper. Taking natural number coding pattern as the classification of the demand level of different progresses, combining with the capacity of progress and length of feeders as the initial solution, establishing the objective function as a fitness function of Tabu Search Algorithm [6], the optimal solution can be obtained. The detailed flow is shown in Fig.5.

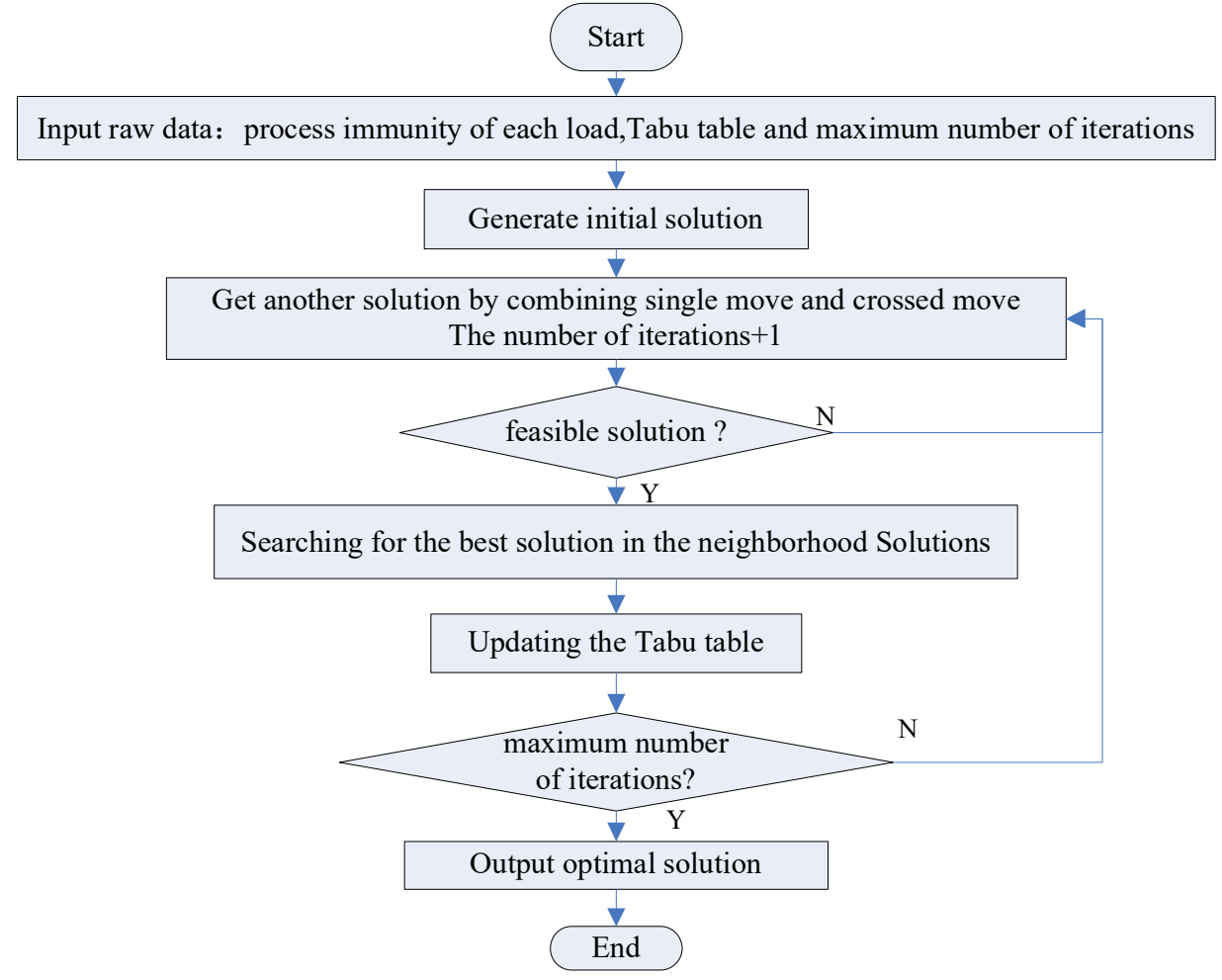

Fig. 5. Flow chart of Tabu search 


\section{Simulation Analysis}

All manuscripts must be in English, also the table and figure texts, otherwise we cannot publish your paper. As a case study, a typical industrial park including three factories is used in the simulation. The industrial process, rated power and major process equipment of each factory is shown in Table 2.

Table 2. Typical in customers in PPP

\begin{tabular}{c|c|c|c}
\hline Customers & Industrial process & Rrated capacity & Technical equipment \\
\hline \multirow{4}{*}{ Paper mill } & Treatments of wood & $200 \mathrm{~kW}$ & Flaker \\
\cline { 2 - 4 } & Refinery of wood pulp & $800 \mathrm{~kW}$ & Water pump \\
\cline { 2 - 4 } & Management of wood chip & $22 \mathrm{~kW}$ & Blower \\
\hline \multirow{4}{*}{ Pharmaceutical factory } & Port pressure maintained & $560 \mathrm{~kW}$ & Ventilator \\
\cline { 2 - 4 } & $\begin{array}{c}\text { Environmental pressure } \\
\text { maintained }\end{array}$ & $500 \mathrm{~kW}$ & Booster pump \\
\cline { 2 - 4 } & Cleanliness maintained & $4 \mathrm{~kW}$ & Transducers \\
\hline \multirow{2}{*}{ Chemical plant } & Temperature control & $160 \mathrm{~kW}$ & Condenser fan \\
\cline { 2 - 4 } & Products separation & $880 \mathrm{~kW}$ & Centrifugal pump \\
\cline { 2 - 4 } & Oxygen content measurement & $18 \mathrm{~kW}$ & Oxygen measuring device \\
\hline
\end{tabular}

The first step is to obtain physical parameters curve and PITs of progresses under various magnitude based on PSCAD / EMTDC simulation. Then the quantitative power demand of each customer can be determined with the proposed method. In the wood processing case, combined with its production process and principle, the wood cutting machine drives tool rotating to get the wood in a given geometry and dimensional accuracy. When the speed of motor is below $92 \%$ of synchronous speed, cutting speed cannot meet the requirements, which will result in obsolescence of product. Therefore, the physical parameters fit this equation: $P_{\text {limit }}=0.96 \mathrm{~W}_{\mathrm{n}}$. Combined with the relay protection device in PPP, the operation time is $100 \mathrm{~ms} \sim 150 \mathrm{~ms}$. So it is assumed that the duration of sag is $150 \mathrm{~ms}$. And the critical acceptable magnitude for customer is same as the voltage variation magnitude in physical parameters curve in accordance with PIT $=150 \mathrm{~ms}$. The physical parameters curves of wood cutting machine while suffering varying magnitude of voltage sag are shown in Fig. 6 . When the voltage magnitude is equal to $65 \% U_{\mathrm{n}}$, PIT $=500 \mathrm{~ms}$, so the power quality demand of wood processing is: $U_{\text {demand }} \geq 65 \% U_{\mathrm{n}}$. Similarly to the other processes, the voltage quality quantitative demand is shown in Table 3.

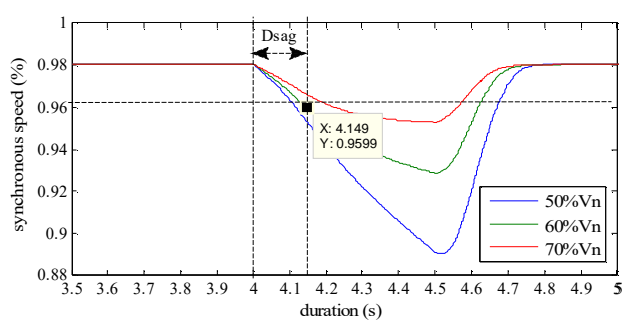

Fig. 6. Response characteristic of wood cutting machine

Table 3. Power quality demand of different sub-processes

\begin{tabular}{c|c|c|c}
\hline Total process & Sub process & $\begin{array}{c}\text { Serial } \\
\text { number }\end{array}$ & Demand for power quality \\
\hline \multirow{4}{*}{ Paper mill } & Flaker & $\mathrm{A}$ & $U_{\text {demand }} \geqslant 60 \% U_{\mathrm{n}}$ \\
\cline { 2 - 4 } & Water pump & $\mathrm{B}$ & $U_{\text {demand }} \geqslant 54 \% U_{\mathrm{n}}$ \\
\cline { 2 - 4 } & Blower & $\mathrm{C}$ & $U_{\text {demand }} \geqslant 80 \% U_{\mathrm{n}}$ \\
\hline \multirow{3}{*}{ Pharmaceutical factory } & Ventilator & $\mathrm{D}$ & $U_{\text {demand }} \geqslant 65 \% U_{\mathrm{n}}$ \\
\cline { 2 - 4 } & Booster pump & $\mathrm{E}$ & $U_{\text {demand }} \geqslant 47 \% U_{\mathrm{n}}$ \\
\cline { 2 - 4 } & Transducers & $\mathrm{F}$ & $U_{\text {demand }} \geqslant 82 \% U_{\mathrm{n}}$ \\
\hline \multirow{3}{*}{ Chemical plant } & Condenser fan & $\mathrm{G}$ & $U_{\text {demand }} \geqslant 62 \% U_{\mathrm{n}}$ \\
\cline { 2 - 4 } & Centrifugal pump & $\mathrm{H}$ & $U_{\text {demand }} \geqslant 43 \% U_{\mathrm{n}}$ \\
\cline { 2 - 4 } & Oxygen measuring device & $\mathrm{I}$ & $U_{\text {demand }} \geqslant 85 \% U_{\mathrm{n}}$ \\
\hline
\end{tabular}

Based on the power quality quantitative demand, the optimization configuration scheme of PPP is shown in Fig. 7(a). The capacities of DVRs are 598kVA, 1177kVA and 44KVA respectively. The traditional optimization configuration scheme considering industrial type of customers is shown in Fig. 7(b). The capacity of DVR and the investment costs of DVR and feeders of both schemes are shown in Table 4. 


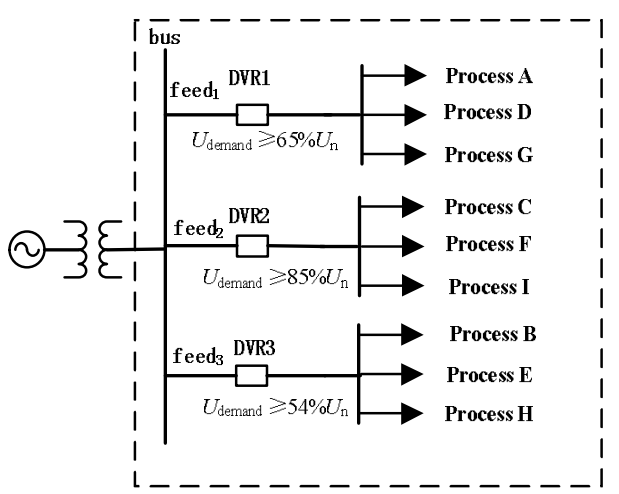

(a) The proposed scheme

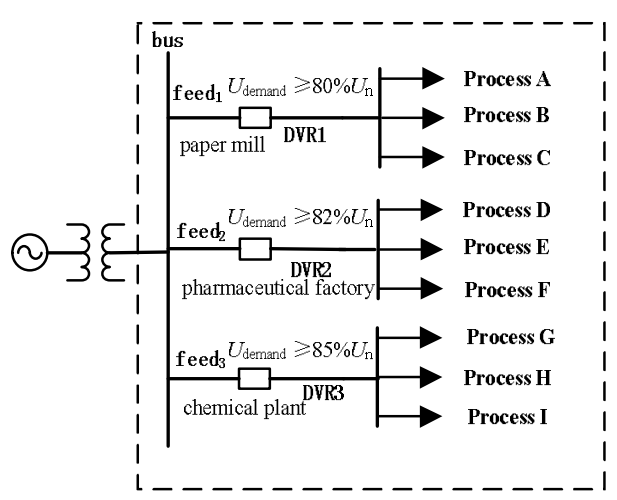

(b) The traditional scheme

Fig. 7. Optimization configuration in PPP

Table 4. Economic comparison of different solutions

\begin{tabular}{ccc|c|c}
\hline \multirow{2}{*}{ Technical solutions } & \multirow{2}{*}{ Total capacity of DVR (kVA) } & \multicolumn{3}{c}{ Investment (RMB) } \\
\cline { 3 - 5 } & & total & DVR & feeders \\
\hline Proposed solutions & 666.40 & 2238600 & 1951600 & 287000 \\
Traditional solutions & 643.98 & 2875500 & 2718500 & 157000 \\
\hline
\end{tabular}

Due to the concentrative geographical location of the same kind customer, the investment of feeders of traditional program is better. But the investment cost for DVR considering power quality levels is much less than the former. Taken as a whole, the proposed optimal configuration method can solve the problem of various demands of customers for power quality at a lower cost.

\section{Conclusion}

1) The quantitative method of customers' power demand based on PIT and physical parameter curve builds the relationship between voltage sag characteristics and acceptable level of customers, which is the basis for the optimal configuration of PPP.

2) The optimal configuration method of PPP proposed in this paper, can not only meet different demands for power quality, but also would ensure a minimum total investment, possesses both theoretical and practical significance.

Besides voltage sag, the other power quality problems such as harmonics, voltage unbalance should be solved urgently in the research about PPP. The complex demand quantitative method for power quality and assorted optimization configuration of custom power devices will be the focus in the further research.

\section{References}

[1] M. Delfantia, S. Quaiab: Analysis and comparison of premium power park performances. Electric Power Systems Research Vol. 83(2012), p. 176-184.

[2] M. Farhoodnea, A. Mohamed and H. Sharee: Power quality improvement using an enhanced premium power park configuration. Power Engineering and Optimization Conference (2012).

[3] CIGRE/CIRED/UIE Joint Working Group C4.110 Voltage dip immunity of equipment and installations. Paris, France (2010).

[4] J.Y. Chan, J.V. Milanovic and A. Delahunty: Risk-based assessment of financial losses due to voltage sag. IEEE Transactions on Power Delivery Vol.26(2011), p. 492-500.

[5] R.C. Degeneff, R. Barss, S. Raedy: Reducing the effect of sags and momentary interruptions: A total owning cost prospective. Harmonics and Quality of Power, Orlando (2000).

[6] K.Nara: A least cost planning method of FRIENDS. PES Power Systems Conference and Exposition. New York, United states(2004). 